\title{
Analysis on Spatiotemporal Distribution Features of Heavy Metals in Soil-Rice Agricultural System in Zhangjiagang City, China
}

\author{
Weihong Zhou ${ }^{1,2}$, Xiaoxiao $\mathrm{Hu}^{1}$, Jianlong $\mathrm{Li}^{1,{ }^{1}}$ and Zhengguo Sun ${ }^{1,3, *}$ \\ ${ }^{1}$ School of Life Sciences, Nanjing University, Nanjing, China \\ ${ }^{2}$ School of Metallurgical and Materials Engineering, Jiangsu University of Science and Technology, Zhangjiagang, China \\ ${ }^{3}$ College of Pratacultural Science, Nanjing Agricultural University, Nanjing, China \\ *Corresponding author
}

\begin{abstract}
To assess the impact of heavy metal contamination on the soil-rice agricultural ecosystem, the distribution of heavy metals in Zhangjiagang City was analyzed by taking samples from the paddy fields. The result show that contents of $\mathrm{Cu}, \mathrm{Pb}$ in soil were increased and here are analogous pollution sources due to the similar spatial distribution of $\mathrm{Cr}$ and $\mathrm{Zn}$. Concentration of heavy metals vary in different organs of rice, and the bioaccumulation pattern is root $>$ leaf $>$ grain. The enrichment capabilities for different heavy metal elements in same rice organ followed an order of $\mathrm{Cu}>\mathrm{Pb}>\mathrm{Zn}>\mathrm{Cr}$ for root, $\mathrm{Pb}>\mathrm{Zn}>\mathrm{Cu}>\mathrm{Cr}$ for leaf, and $\mathrm{Zn}$ is slightly higher than $\mathrm{Cu}$ in grain. The comprehensive pollution index of the soil was lower than 1 ; The grain of the rice is slightly polluted by $\mathrm{Cr}$ in the sampling point of HPC and its single factor indexes of $\mathrm{Cu}$ and $\mathrm{Zn}$ were both higher than the other sampling sites, while the rice grain is less polluted in other study areas. Therefore, it is necessary to ensure grain quality safety based on the accumulation coefficient characteristics and the spatial distribution of heavy metal pollution. This research offers scientific evidences and data references for local policy makers to rightly maintain the safety and sustainability of agriculture ecosystem in Zhangjiagang City.
\end{abstract}

Keywords-heavy metals; spatiotemporal distribution; accumulation coefficient; spatial interpolation; integrated pollution index; grain safety

\section{INTRODUCTION}

Food security has attracted more and more attention in modern agriculture research [1-2], which has become a globally recognized issue [3-4].Soil is the main source of contamination of food plant with heavy metals [5]. From the existing literatures, heavy metals are potentially toxic to crops, animals and humans when contaminated soils are used for crop production [6]. Heavy metals can accumulate in the crop field and transfer in to crop at toxic levels due to its cumulative nature [7].

With the development of urbanization and industrialization, the quantity and the quality of farmland are both decreasing [8] and in China in particular. As the representative of China's newly developing small city, urbanization and industrialization process in Zhangjiagang is fast. However, the rapid development in Zhangjiagang has led to significant release of waste into the environment, including heavy metals contamination of the soil [9]. Therefore, a more detailed study is required to elucidate the environmental changes associated with the rapid urbanization.

Soil-rice system is chosen as the research object, the spatial distribution, accumulation and transformation process of heavy metals are analyzed and heavy metal pollution in farmland soil and pollution on grain quality and security are also evaluated. The main research procedure is as follows:

1) Collected soil and rice samples in the research area during 2010-2011.

2) Tested the heavy metals content of the collected samples and calculated the integrated pollution index of heavy metals.

3) Using GIS method to study the spatiotemporal distribution features of heavy metals.

4) Analyzed the present situation of heavy metals pollution in soil-rice agricultural system in study area.

\section{MATERIALS AND MethodS}

\section{A. Study Area}

The study area, Zhangjiagang city, which is situated on a flat alluvial plain in the Yangtze River delta $\left(31^{\circ} 43^{\prime} \sim 32^{\circ} 02^{\prime} \mathrm{N}\right.$, $120^{\circ} 21^{\prime} \sim 120^{\circ} 52^{\prime}$ E), an administrative district covering $998.48 \mathrm{~km}^{2}$ with a population of around $1,250,000$. The site is within subtropical maritime monsoon climate and the dominant wind direction is southeast wind, with average annual temperature is $15.2^{\circ} \mathrm{C}$, annual precipitation is $1042.9 \mathrm{~mm}$ and average mean sunshine duration is 2047.5h. The main soil type in Zhangjiagang is tide soil and paddy soil, which is suitable for planting rice, wheat and rapeseed. With an over $60 \%$ share in the county's total GDP, common industries in the city include metallurgical, chemical, electroplating, printing and dyeing, and paper-making.

\section{B. Data Collection and Treatment}

Soil and rice samples were collected from paddy fields in Zhangjiagang city. 20 samples of topsoil $(0-20 \mathrm{~cm})$ and rice residual root were collected in Dec. 2010, and 15 samples of topsoil, rice roots, leaves and grain samples were collected in Oct 2011. 
Single factor index and Nemerow integrated pollution index were used to evaluate heavy metals pollution situation of surface soil and rice grain. Then the accumulation coefficient of rice root, leaf, grain was calculated.

The accumulation coefficient of heavy metals is measured by the ratio of metal concentrations in plans or one organ to metal concentrations in that soil.

Single factor index is commonly calculated using the following formulae:

$$
P_{i}=C_{i} / S_{i}
$$

where $\mathrm{P}_{\mathrm{i}}$ is the single factor pollution index of i pollutant, $\mathrm{C}_{i}$ represents the pollutants measured value and $S_{i}$ means China's national standard

Nemerow integrated pollution index's equation is given as under:

$$
P_{N}=\left[\left(P_{\max }^{2}+P_{\text {avg }}^{2}\right) / 2\right]^{1 / 2}
$$

where $\mathrm{P}_{\mathrm{N}}$ is the integrated pollution index, $\mathrm{P}_{\max }$ is the max value of single factor pollution index and $\mathrm{P}_{\mathrm{avg}}$ is the mean value of single factor pollution index. The classification criterions are presented in TABLE1.
TABLE I. CLASSIFICATION CRITERIONS FOR POLLUTION INDEX.

\begin{tabular}{ccc}
\hline Level & Nemerow Index & Appraisal result \\
\hline 1 & $P_{N} \leq 0.7$ & Very Clean \\
2 & $0.7<P_{N} \leq 1.0$ & Clean \\
3 & $1.0<P_{N} \leq 2.0$ & Mild pollution \\
4 & $2.0<P_{N} \leq 3.0$ & Moderate pollution \\
5 & $P_{N}>3.0$ & Severe pollution \\
\hline
\end{tabular}

\section{Data Processing}

Heavy metal contents in soil-rice agricultural system and accumulation coefficient is calculated in Excel 2007 for graphing and analysis soil, rice grain quality evaluation results The spatial distribution of heavy metal contents is analyzed by inverse distance weighting interpolation (IDW) use ArcGIS 10.3.

\section{RESULTS AND ANALYSIS}

\section{A. Spatiotemporal Distribution of Copper and Lead in Soil}

FIGURE1 shows concentrations of $\mathrm{Cu}, \mathrm{Pb}$ in soil were increased in 2011compared with they are in 2010. From 2010 to 2011, content of $\mathrm{Cu}$ in the southern area, $\mathrm{Pb}$ in the southern and eastern is low. However it cannot explain the spatial variations of $\mathrm{Cu}$ and $\mathrm{Pb}$ in soil because of the lack of more years' data.
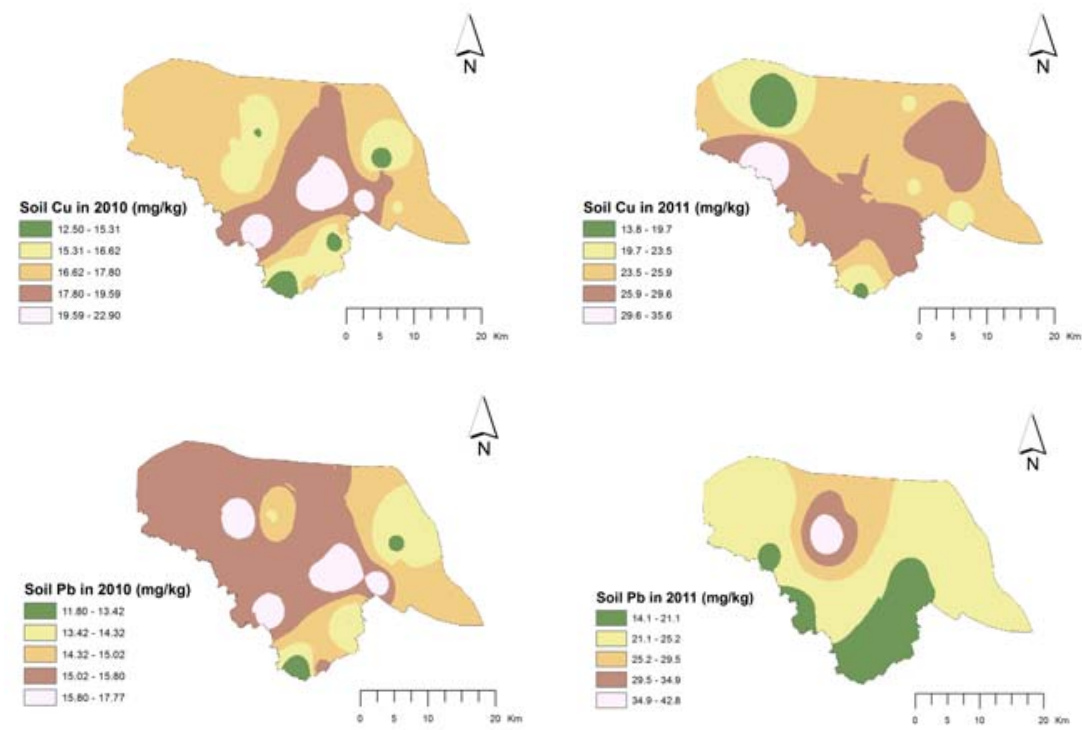

FIGURE I. SPATIOTEMPORAL DISTRIBUTION PATTERNS OF SOIL COPPER AND SOIL LEAD ESTIMATED BY IDW.

\section{B. Spatial Distribution of Cadmium and Zinc in Soil-Rice Agricultural System}

FIGURE2 shows that the soil $\mathrm{Cr}$ in the research area is dispersed distribution. The grain $\mathrm{Cr}$ has higher concentration in the northern area than in other place. In Western area, concentrations of soil $\mathrm{Zn}$ and grain $\mathrm{Zn}$ are low. Soil $\mathrm{Zn}$ in central area is slightly higher than eastern area and is dispersed distribution. Concentration of rice grain $\mathrm{Zn}$ in eastern area is slightly higher than it in western area and in the central partial southeast area it has a relatively high area. Whether in the soil or in rice grain, spatial distribution of $\mathrm{Cr}$ and $\mathrm{Zn}$ are very similar. 

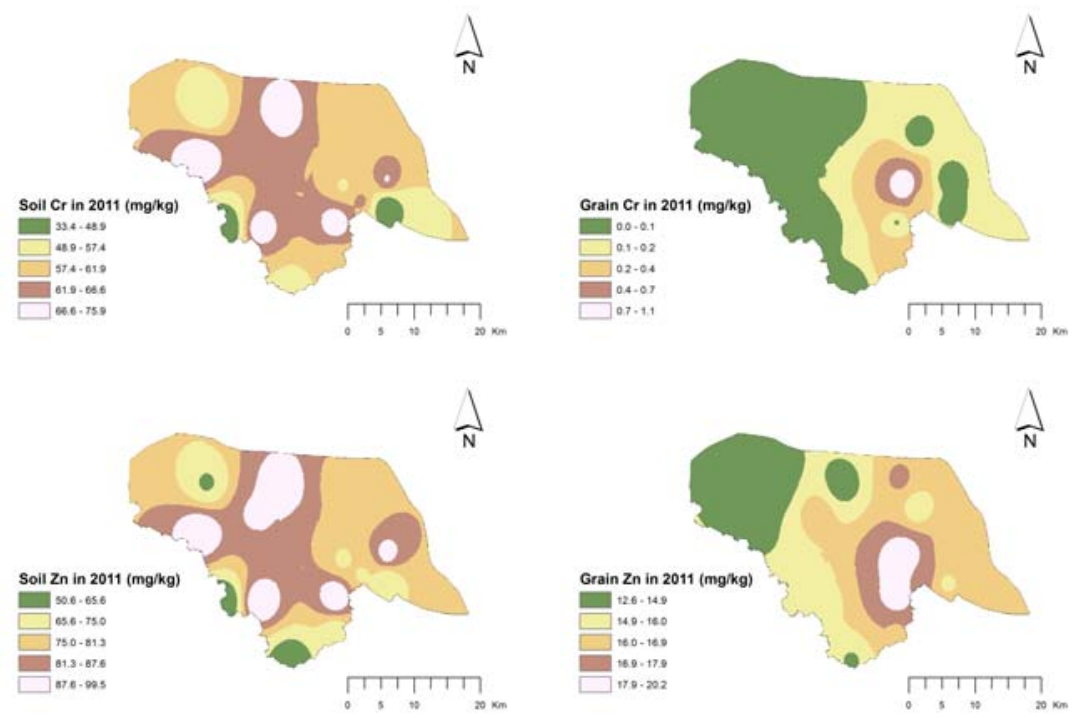

FIGURE II. SPATIAL DISTRIBUTION PATTERNS OF CADMIUM AND ZINC OF SOIL AND GRAIN IN 2011 ESTIMATED BY IDW.

C. Analysis on Heavy Metals Accumulation Coefficient of Rice Root, Leaf and Grain

Different rice organs have different enrichment ability. TABLE2 shows that enrichment ability from big to small arrangement of rice organs is root $>$ leaf $>$ grain. The same organ has different enrichment ability to different heavy metal elements. In this research, heavy metals absorbed ability arrangement is: $\mathrm{Cu}>\mathrm{Pb}>\mathrm{Zn}>\mathrm{Cr}$ in root and $\mathrm{Pb}>\mathrm{Zn}>\mathrm{Cu}>$ $\mathrm{Cr}$ in leaf and $\mathrm{Zn}$ is slightly higher than $\mathrm{Cu}$ in grain.

TABLE II. ACCUMULATION COEFFICIENT TO HEAVY METALS OF RICE ROOT, LEAF AND GRAIN.

\begin{tabular}{|c|c|c|c|c|c|c|c|c|c|c|}
\hline $\begin{array}{c}\text { Sampling Point } \\
\text { Name }\end{array}$ & $\begin{array}{c}\text { Root } \\
\text { Cr }\end{array}$ & $\begin{array}{c}\text { Leaf } \\
\text { Cr }\end{array}$ & $\begin{array}{c}\text { Root } \\
\text { Cu }\end{array}$ & $\begin{array}{c}\text { Leaf } \\
\text { Cu }\end{array}$ & $\begin{array}{c}\text { Grain } \\
\text { Cu }\end{array}$ & $\begin{array}{c}\text { Root } \\
\text { Pb }\end{array}$ & $\begin{array}{c}\text { Leaf } \\
\mathbf{P b}\end{array}$ & $\begin{array}{c}\text { Root } \\
\text { Zn }\end{array}$ & $\begin{array}{c}\text { Leaf } \\
\text { Zn }\end{array}$ & $\begin{array}{c}\text { Grain } \\
\text { Zn } \\
\end{array}$ \\
\hline CYS & 0.12 & 0.13 & 0.68 & 0.19 & 0.17 & 0.57 & 0.44 & 0.60 & 0.36 & 0.24 \\
\hline CB & 0.17 & 0.20 & 1.46 & 0.25 & 0.19 & 0.88 & 0.40 & 0.57 & 0.33 & 0.18 \\
\hline YL & 0.15 & 0.06 & 1.30 & 0.32 & 0.24 & 0.81 & 1.22 & 0.50 & 0.37 & 0.23 \\
\hline OQ & 0.21 & 0.06 & 0.91 & 0.22 & 0.12 & 1.19 & 0.69 & 0.93 & 0.29 & 0.19 \\
\hline QXQ & 0.21 & 0.05 & 1.00 & 0.25 & 0.15 & 2.20 & 1.02 & 0.82 & 0.49 & 0.24 \\
\hline GZ & 0.21 & 0.24 & 0.69 & 0.18 & 0.09 & 1.93 & 0.58 & 1.44 & 0.54 & 0.28 \\
\hline $\mathrm{AQ}$ & 0.21 & 0.07 & 1.27 & 0.20 & 0.15 & 1.16 & 0.55 & 0.71 & 0.43 & 0.16 \\
\hline HT & 0.23 & 0.07 & 0.83 & 0.20 & 0.14 & 0.72 & 0.72 & 0.98 & 0.57 & 0.31 \\
\hline SG & 0.56 & 0.06 & 1.63 & 0.22 & 0.17 & 0.79 & 0.74 & 0.78 & 0.54 & 0.15 \\
\hline DJC & 0.33 & 0.25 & 1.68 & 0.54 & 0.34 & 1.00 & 0.42 & 1.16 & 0.69 & 0.20 \\
\hline HX & 0.10 & 0.14 & 0.92 & 0.24 & 0.17 & 0.52 & 0.28 & 0.76 & 0.51 & 0.19 \\
\hline $\mathrm{JF}$ & 0.20 & 0.11 & 1.56 & 0.20 & 0.17 & 0.67 & 0.42 & 0.60 & 0.39 & 0.15 \\
\hline YYMT & 0.25 & 0.13 & 1.17 & 0.23 & 0.20 & 0.52 & 0.34 & 0.70 & 0.36 & 0.22 \\
\hline TJC & 0.14 & 0.23 & 1.25 & 0.19 & 0.19 & 0.70 & 0.41 & 0.67 & 0.29 & 0.20 \\
\hline HPC & 0.36 & 0.14 & 1.67 & 0.24 & 0.27 & 0.77 & 0.75 & 0.52 & 0.43 & 0.28 \\
\hline
\end{tabular}

D. Effect of Soil Heavy Metal Accumulation and Transfer on Grain Quality and Security

- Assessment of farmland soil pollution: As summarized in TABLE3, in 2011 Nemerow integrated pollution index in soil average value is 0.300 , which indicates that the farmland soil is clean in the study area. But compared with two years of pollution evaluation results, farmland soil are still facing a threat from heavy metal contaminate. For example, the average value of Nemerow integrated pollution index in 2011 is also higher than in 2010 (from 0.210 to 0.300 ). 
TABLE III. POLLUTION INDEXES OF SOIL HEAVY METALS.

\begin{tabular}{clll}
\hline $\begin{array}{c}\text { Sampling Point } \\
\text { Name }\end{array}$ & \multicolumn{2}{c}{ Single factor index } & PN \\
\hline Averages in 2010 & 0.186 & $\mathrm{Cu}$ & \\
Averages in 2011 & 0.283 & 0.172 & 0.210 \\
\hline
\end{tabular}

- Analysis of rice root, leaf and grain pollution: The pollution index of rice grain heavy metals in 2011 are list in TABLE 4, single factor index of rice grain $\mathrm{Cr}$ in HPC sample point is 1.060, which shows mild pollution. And its single factor indexes of $\mathrm{Cu}$ and $\mathrm{Zn}$ were both higher than the other sampling sites. Single factor index values in the rest of the sample points are extremely low, which shows no pollution. Single factor variation of $\mathrm{Cu}$ and $\mathrm{Zn}$ is in the range of 0.178 0.620 and $0.252-0.404$, separately, which show no pollution. Nemerow integrated pollution index is in the range of $0.236-0.896$ (average value is 0.407 ). All the values of Nemerow integrated pollution indexes in sample points are less than 1 , which shows no pollution in study area. However, Single factor index value of $\mathrm{Cr}, \mathrm{Cu}, \mathrm{Zn}$ and Nemerow integrated pollution index in HPC sample point are the highest of all the sample points, which shows potential pollution threat.

TABLE IV. POLLUTION INDEXES OF RICE GRAIN HEAVY METALS IN 2011.

\begin{tabular}{ccccc}
\hline \multirow{2}{*}{$\begin{array}{c}\text { Sampling Point } \\
\text { Name }\end{array}$} & \multicolumn{3}{c}{ Single factor index } & Plant PN \\
& Cr & Cu & Zn & \\
\hline CYS & 0.000 & 0.360 & 0.314 & 0.300 \\
CB & 0.000 & 0.534 & 0.330 & 0.429 \\
YL & 0.240 & 0.591 & 0.344 & 0.501 \\
OQ & 0.080 & 0.358 & 0.374 & 0.326 \\
QXQ & 0.360 & 0.414 & 0.334 & 0.392 \\
GZ & 0.000 & 0.178 & 0.294 & 0.236 \\
AQ & 0.000 & 0.431 & 0.308 & 0.351 \\
HT & 0.000 & 0.349 & 0.314 & 0.292 \\
SG & 0.000 & 0.594 & 0.290 & 0.469 \\
DJC & 0.050 & 0.473 & 0.252 & 0.381 \\
HX & 0.050 & 0.436 & 0.336 & 0.364 \\
JF & 0.000 & 0.413 & 0.278 & 0.334 \\
YYMT & 0.130 & 0.454 & 0.342 & 0.388 \\
TJC & 0.000 & 0.552 & 0.304 & 0.439 \\
HPC & 1.060 & 0.620 & 0.404 & 0.896 \\
\hline Averages & 0.131 & 0.450 & 0.321 & 0.407 \\
\hline & & & &
\end{tabular}

IV. CONCLUSIONS

The concentration of soil $\mathrm{Cu}, \mathrm{Pb}$ in 2011 is higher than those in 2010. These two elements may have a common way into farmland. Heavy metals content of the south area are generally lower than the other areas and the comprehensive evaluation result is ideal. While whether in the soil or in rice grain, spatial distribution of $\mathrm{Cr}$ and $\mathrm{Zn}$ are very similar.

In rice organs, the bioaccumulation pattern is root $>$ leaf $>$ grain. The enrichment ability sequence of root and leaf to different heavy metal elements is $\mathrm{Cu}>\mathrm{Pb}>\mathrm{Zn}>\mathrm{Cr}$ and $\mathrm{Pb}>$ $\mathrm{Zn}>\mathrm{Cu}>\mathrm{Cr}$, respectively. The enrichment ability of $\mathrm{Zn}$ in grain is slightly higher than $\mathrm{Cu}$. There is little enrichment of grain to $\mathrm{Cr}$ and $\mathrm{Pb}$.

In 2011 Nemerow integrated pollution index in soil average value is 0.3 , which indicates that the farmland soil is clean in Zhangjiagang city, but compared with two years of pollution evaluation results, farmland soil are still facing a threat from heavy metal contaminate.

The average values of single factor index of $\mathrm{Cr}, \mathrm{Cu}$ and $\mathrm{Zn}$ in rice grain are $0.131,0.450$ and 0.321 , respectively, and the average value of Nemerow integrated pollution index is 0.407 , which reflects the quality safety of rice grain in Zhangjiagang. However, in HPC sample point, the single factor index values of $\mathrm{Cr}, \mathrm{Cu}$ and $\mathrm{Zn}$ is obviously higher than the other sample points (especially $\mathrm{Cr}$ is slightly higher than its national standards).

Generally speaking, the result of comprehensive evaluation to soil and rice grain shows that the grain quality is safe in Zhangjiagang. However, the industry of Zhangjiagang city is developing rapidly in recent years and the potential pollution threat is continuously increasing. A more detailed research is needed to understand the distribution characteristics of heavy metals and its accumulation and transformation in soil-crop system. Then the grain quality and safety could be ensured.

\section{ACKNOWLEDGMENT}

We are grateful to the chief editor and anonymous reviewers for illuminating comments. This research was supported by "The Jiangsu Province Natural Science Foundation Project of China (BK20140413), the Jiangsu Province Agricultural Three Renovations Project of China (SXGC [2014]287), the Suzhou Science and Technology Project of China (SNG201447), the Nutritive Physiology, Decay Mechanism and Preservation Research of Fenghuang Water Peach in Zhangjiagang City (ZKN1002) and the National Natural Science Foundation Project of China (41271361)”.

\section{REFERENCES}

[1] Martin H, Thomas J, Willi M. Grain: a stream cipher for constrained environments. International Journal of Wireless and Mobile Computing, 2007, 2(1):86-93.

[2] Brown M E, Beat H, Nathaniel H. Markets, climate change, and food security in west Africa. Environment Science and Techology, 2009, 43(21): 8016-8020.

[3] Wang H, Zhang M, Cai Y. Problems, challenges, and strategic options of grain security in China. Advances in Agronomy, 2009, 103(9): 101-147.

[4] Shi WX. The goal and risk analysis on China's grain security. Issues in Agricultural Economy, 2009, 5: 12-16.

[5] Rogival D, Scheirs J, Blust R. Transfer and accumulation of metals in a soil-diet-wood mouse food chain along a metal pollution gradient. Environment Pollution, 2007, 145(2):516-528. 
[6] Xian X. Response of kidney bean to concentration and chemical form of cadmium, zinc and lead in polluted soils. Environment Pollution, 1989,57:127-137.

[7] N.Gupta, D.K.Khan, S.C.Santra. Heavy metal accumulation in vegetables grown in a long-term wastewater-irrigated agricultural land of tropical India. Environmental Monitoring and Assessment, 2012,184(11):6673-6682.

[8] Lonsdorf E, Kremen C, Ricketts T, Winfree R, Williams N, Greenleaf S. Modelling pollination services across agricultural landscapes. Annals of Botany, 2009, 103(9): 1589-1600.

[9] Huang B, Wang M, Yan LX, Sun WX, Zhao YC, Shi XZ, David C. Weidorf. Accumulation, transfer, and environmental risk of soil mercury in a rapidly industrializing region of the Yangtze River Delta, China. Journal of Soils and Sediments, 2011, 11(4):607-618. 